\title{
«Im Zentrum der SULM wie der «pipette> steht die Einheit in der Vielfalt»
}

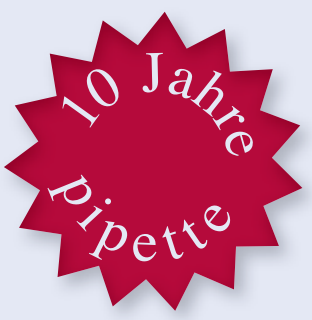

Die «pipette», das offizielle Organ der Schweizerischen Union für Labormedizin (SULM), feiert in diesem Jahr ihr 10-jähriges Bestehen. Anlass genug für ein kurzes Interview mit Chefredaktor Andreas R. Huber zum Konzept und den Zielen der Zeitschrift.

Die «pipette - Swiss Laboratory Medicine» - richtet sich gemäss Homepage der SULM «u.a. an Klinische Chemiker, Mikrobiologen, Genetiker, Hämatologen, Endokrinologen, Allergologen, Immunologen, biomedizinische Analytikerinnen, medizinische Praxisassistentinnen und Hausärzte». Ist es nicht ein zu hoher Anspruch, ein derart heterogenes Zielpublikum anzuvisieren?

Andreas R. Huber: Das ist richtig, es scheint ein grosser Spagat zu sein. Allerdings gibt es einen zentralen gemeinsamen Nenner. Alle erwähnten Fachpersonen führen Laboranalysen durch bzw. geben sie in Auftrag und brauchen deren Resultate zur Arbeit mit ihren Patientinnen und Patienten. Dazu braucht es ein profundes Wissen, um die Technologien, Möglichkeiten und Grenzen zu begreifen. Ohne dieses Wissen kann Labormedizin nicht sinnvoll angewendet werden.

Auf welche Weise versuchen Sie, den unterschiedlichenErwartungen an die «pipette» gerecht zu werden?

Wir versuchen, uns auf das Verbindende zu fokussieren: Wie funktioniert die Analytik? Wo sind die Fallstricke? Wie verbessere ich Diagnose, Therapie, Prognose und vor allem den Outcome? Und last but not least die Kostenlast?

Nach welchen Kriterien planen Sie Ihre Ausgaben?

Wir publizieren Themenhefte und begleiten sie durch aktuelle gesundheitspolitische Artikel. Dabei sollen die verschiedenen Fachgebiete ausgewogen behandelt werden - mit Blick auf die gesamte Labormedizin.

Wie die Medizin insgesamt hat sich auch die Labormedizin in den vergangenen zehn Jahren stark weiterentwickelt. Haben diese Entwicklungen auch ihren Niederschlag im Konzept der «pipette» gefunden?

Ja. Wir sind zeitnaher und können uns mehr als früher darauf verlassen, dass das Wissen um Labormedizin zugenommen hat. Darauf bauen wir auf.
Beobachten Sie eine Verschiebung der Themenschwerpunkte in der vergangenen Dekade?

Weg von Methodenbeschrieb und bekannten Technologien, hin zu Genomics, Proteomics, Metabolomics, aber auch zu Megadata, Vernetzung und Outcome für Patient und Gesellschaft.

Was sind gegenwärtig die «Hot Topics» in der Labormedizin?

Neben den eben genannten sind dies vor allem auch die Automation und neue Messmethoden.

Wie kommen Sie zu Ihren Artikeln, wer sind Ihre Autoren? Dank guter Vernetzung mit Institutsleitern, Chefärzten und Forschern sind angefragte Kollegen meist bereit, einen Artikel zu schreiben. Wir haben auch spontan eingereichte Artikel und standespolitische

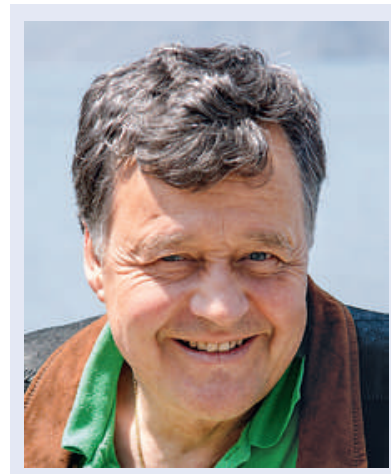

\section{Andreas R. Huber}

Professor Dr. med. Andreas R. Huber ist seit 10 Jahren Chefredaktor der «pipette». Hauptberuflich ist der Internist mit Spezialisierungen in Onkologie und Hämatologie als Chefarzt und Leiter des Zentrums für Labormedizin im Kantonsspital Aarau tätig. Andreas Huber ist verheiratet und Vater von drei Söhnen. 


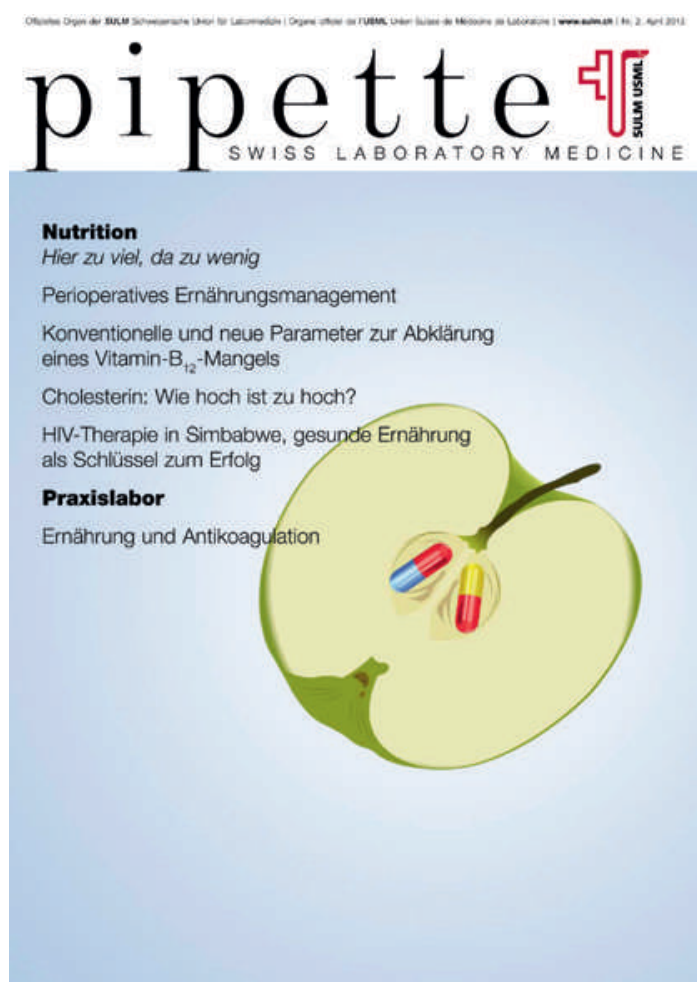

Die «pipette» ist das offizielle Organ der Schweizerischen Union für Labormedizin SULM.

Mitteilungen. Die allermeisten Artikel in der «pipette» sind aber Erstartikel, die gezielt für unsere Themenhefte verfasst werden.

\section{«Die «pipette» hat wie die SULM die Aufgabe, ein Sprachrohr für alle in der Labormedizin Involvierten} zu sein.»

Wie ist die Redaktion zusammengesetzt und welche Aufgaben nehmen die Redaktorinnen und Redaktoren wahr? Wir versuchen die Fachgebiete ausgeglichen abzubilden und den Röstigraben wie auch den Geschlechterkampf fair zu überbrücken. Trotz aller Parität suchen wir letztlich geeignete Personen, die ins Team passen und gewillt sind, die Fronarbeit zu leisten.

Die «pipette» ist das offizielle Organ der SULM. Wie sind die Kompetenzen zwischen Verbandsspitze und Redaktion verteilt?

Im Redaktionskomitee der «pipette» ist der SULMVorstand mit zwei Personen vertreten. In der Geschäftsleitung der «pipette» arbeiten - neben den
Vertretern des EMH-Verlages - drei SULM-Vorstandsmitglieder mit. Die «pipette» hat wie die SULM die Aufgabe, ein Sprachrohr für alle in der Labormedizin Involvierten zu sein. Sie ist aber redaktionell absolut unabhängig und finanziert sich durch Inserate. Die SULM erwartet keine Einnahmenüberschüsse, gleichzeitig aber auch eine sogenannte «Schwarze Null». Wie der SULM-Vorstand, arbeiten auch die Redaktoren und Autoren ehrenamtlich.

Inwieweit ist die "pipette» neben einer Fachzeitschrift eine verbandspolitische Zeitschrift?

Auch dies ist ein Spagat, schon alleine aufgrund der sehr heterogen strukturierten Labormedizin. Verbandspolitik muss und soll aber Platz haben. Die «pipette» als Organ der SULM kann und darf aber nicht ein Medium nur für eine Fachrichtung sein. Im Zentrum der SULM wie der «pipette» steht die Einheit in der Vielfalt. Wir erleben in der Medizin starke «Teile und herrsche»-Tendenzen. Man kann ihnen nur vereint Paroli bieten.

Versuchen Sie, mit der «pipette» politisch mitgesteuerte Prozesse zu beeinflussen, etwa die Tarifgestaltung im Bereich der Praxislabors?

Wir versuchen, die Qualität zu verbessern, bei allen Anwendern von Laboranalytik. Weiter geht es um die Darstellung des Nutzens von Labormedizin im Rahmen des Patientenprozesses. Bezüglich Tarifgestaltung sind wir sehr zurückhaltend. Eine hohe Qualität und eine hohe Effektivität verdienen auch einen adäquaten Tarif. Deshalb sind für uns Artikel wichtig, die den Nutzen im Vergleich zu anderen medizinischen Massnahmen aufzeigen.

Welche Zukunftspläne und Wünsche haben Sie als Chefredaktor für Ihre Zeitschrift?

Aktive, jüngere Autoren und Redaktoren, Akzeptanz der Labormedizin als innovatives Fachgebiet der Medizin und eine deutlich bessere Vernetzung mit den Chefredaktoren der anderen EMH-Zeitschriften.

«pipette»
Die 2004 gegründete «pipette» ist das offizielle
Organ der Schweizerischen Union für Laborme-
dizin SULM und pflegt eine wissenschaftliche,
gut recherchierte, personalisierte und klar formu-
lierte Berichterstattung. Artikel und Berichte zu
aktuellen Trends aus erster Hand bilden eine
aussagekräftige Stimme im Umfeld der Labor-
medizin. «pipette» erscheint $6 \times$ jährlich in einer
Auflage von 16000 Exemplaren.

